\title{
Pengaruh literasi ekonomi dan literasi keuangan terhadap sikap tentang gaya hidup hedonis mahasiswa aktivis UKM organisasi pecinta musik (OPUS) 275 Universitas Negeri Malang (Gaya hidup hedonis berdasarkan pendapatan)
}

\author{
Nurul Hidayah, Wahjoedi* \\ Universitas Negeri Malang, Jl. Semarang No. 5 Malang, Jawa Timur, Indonesia \\ *Penulis korespondensi, Surel: wahjoedi.fe@um.ac.id
}

Paper received: 6-8-2021; revised: 20-8-2021; accepted: 28-8-2021

\begin{abstract}
Research has been carried out on the effect of economic literacy and financial literacy on attitudes about hedonic lifestyles. This study aims to determine whether there is a partial or simultaneous influence of economic literacy and financial literacy on attitudes about hedonic lifestyles. This study uses a quantitative research method that is explanatory by explaining the effect of the independent variable on the dependent variable. The results showed that there was no significant and significant effect between economic literacy and financial literacy on attitudes about life partially, but there was a significant and significant effect of economic literacy and financial literacy on attitudes about hedonic lifestyles simultaneously.
\end{abstract}

Keywords: economic literacy; financial literacy; hedonic lifestyle

\begin{abstract}
Abstrak
Telah dilakukan penelitian mengenai pengaruh literasi ekonomi dan literasi keuangan terhadap sikap tentang gaya hidup hedonis. Penelitian ini bertujuan untuk mengetahui apakah terdapat pengaruh secara parsial maupun simultan literasi ekonomi dan literasi keuangan terhadap sikap tentang gaya hidup hedonis. Penelitian ini menggunakan metode penelitian kuantitatif yang bersifat eksplanasi dengan menjelaskan pengaruh variabel bebas terhadap variabel terikat. Hasil penelitian menunjukkan tidak terdapat pengaruh dan signifikan antara literasi ekonomi dan literasi keuangan terhadap sikap tentang gaya hidup secara parsial, namun terdapat pengaruh dan signifikan literasi ekonomi dan literasi keuangan terhadap sikap tentang gaya hidup hedonis secara simultan.
\end{abstract}

Kata kunci: literasi ekonomi; literasi keuangan; gaya hidup hedonis

\section{Pendahuluan}

Perkembangan teknologi yang sangat pesat pada zaman globalisasi merupakan salah satu dampak yang memberikan pengaruh besar terhadap perilaku manusia dalam kegiatan sehari-hari dalam membentuk kepribadian dan gaya hidup seseorang. Dengan kemajuan teknologi memberikan kemudahan semua orang dalam mengakses, menerima, dan merespon informasi demi menunjang kelangsungan hidup. Sebagai konsumen akan menunjukkan gaya hidup seseorang dengan menampilkan sikap dan perilaku dalam mengkonsumsi suatu produk dalam jangka waktu yang tidak permanen.

Gaya hidup adalah gambaran seseorang dalam menjalankan kehidupannya sebagai seorang manusia dengan cara bagaimana seseorang memanfaatkan hidupnya, menggunakan uang, dan memanfaatkan waktu yang dimiliki (Priansa, 2017). Gaya hidup setiap orang tentunya berbeda. Konsumen yang memiliki gaya hidup yang sama akan mengelompokkan 
dirinya pada kelompok berdasarkan minat dan waktu senggang yang dimiliki serta membelanjakan uangnya sesuai dengan gaya hidup tersebut (Suryani, 2013). Pada penelitian Nadzir (2015) disebutkan bermacam-macam cara mahasiswa dalam mengisi waktu luang. Kegiatan tersebut didapat dari hasil bersosialisasi antar mahasiswa mengenai ketertarikan tentang gaya hidup dan tren terkini. Lingkungan mahasiswa dan sikap seseorang merupakan salah satu faktor penentu terbentuknya gaya hidup.

Menurut Solihat dan Arnasik (2018) dalam jurnalnya menyatakan bahwa "literasi ekonomi adalah pemahaman dan pengetahuan dasar teori ekonomi, konsep, dan aplikasi". Pemahaman dan pengetahuan ini digunakan untuk pengambilan keputusan dalam memanfaatkan sumber daya yang terbatas guna memenuhi kebutuhan yang tidak terbatas. Sedangkan literasi keuangan menurut Otoritas Jasa Keuangan (2017) adalah suatu pengetahuan, keterampilan, dan keyakinan yang akan mempengaruhi sikap dan perilaku seseorang untuk meningkatkan kualitas dalam pengambilan keputusan serta pengelolaan keuangan demi mencapai kesejahteraan. Otoritas Jasa Keuangan (OJK) (dalam Purnama \& Yuliafitri, 2019) juga menjelaskan literasi keuangan merupakan rangkaian proses atau aktivitas untuk meningkatkan pengetahuan (knowledge), keyakinan (confidence), keterampilan (skill) konsumen masyarakat luas, sehingga masyarakat mampu mengelola keuangan dengan lebih baik. Pentingnya pemahaman mahasiswa tentang literasi ekonomi dan literasi keuangan sangat diperlukan supaya dapat mengambil keputusan dengan bijak dan mampu mengelola keuangan dengan baik demi mencapai kesejahteraan hidup.

Tujuan penelitian ini adalah untuk mengetahui apakah terdapat pengaruh signifikan literasi ekonomi terhadap sikap tentang gaya hidup hedonis mahasiswa aktivis UKM Organisasi Pecinta Musik (OPUS) 275, apakah terdapat pengaruh signifikan literasi keuangan terhadap sikap tentang gaya hidup hedonis mahasiswa aktivis UKM Organisasi Pecinta Musik (OPUS) 275, dan apakah terdapat pengaruh signifikan literasi ekonomi dan literasi keuangan terhadap sikap tentang gaya hidup hedonis mahasiswa aktivis UKM Organisasi Pecinta Musik (OPUS) 275.

\section{Metode}

Jenis penelitian ini yaitu penelitian kuantitatif dan bersifat eksplanasi dimana penelitian berfungsi untuk menjelaskan pengaruh variabel bebas terhadap variabel terikat. Penelitian ini memiliki dua variabel bebas dan satu variabel terikat yaitu literasi ekonomi $\left(\mathrm{X}_{1}\right)$ dan literasi keuangan $\left(\mathrm{X}_{2}\right)$ sebagai variabel bebas dan sikap terhadap gaya hidup hedonis $(\mathrm{Y})$ sebagai variabel terikat. Populasi dalam penelitian ini adalah mahasiswa aktivis UKM Organisasi Pecinta Musik (OPUS) 275 Universitas Negeri Malang yang kegiatan organisasinya bergerak di bidang seni musik. Jumlah populasi dalam penelitian ini sebanyak 78 mahasiswa yang terdiri dari diklat 21 dan diklat 22. Sampel yang digunakan pada penelitian ini sebanyak 65 mahasiswa. Pada penelitian ini teknik pengambilan sampel menggunakan metode simple random sampling.

\subsection{Instrumen Penelitian}

Instrumen yang digunakan pada penelitian ini berupa kuesioner atau angket dimana responden akan menjawab pertanyaan tertulis untuk dianalisis oleh peneliti. Angket yang digunakan pada penelitian ini berupa angket tertutup dimana terdapat pertanyaan dan pernyataan dengan menyediakan jawaban-jawaban yang akan dipilih oleh responden. 
Instrumen penelitian variabel literasi ekonomi mengacu pada indikator National Council of Economic Education (NCEE) (dalam Haryono, 2013) yang terdiri dari 20 indikator, variabel literasi keuangan mengacu pada indikator Waluyo dan Marlina (2019) yang terdiri dari 15 indikator, dan variabel gaya hidup hedonis mengacu pada indikator Nadzir (2015) yang terdiri dari 15 indikator.

\subsection{Instrumen Pengukuran}

Alat ukur yang digunakan adalah skala likert. Alat uji instrumen pada penelitian ini yaitu uji validitas dan uji reabilitas. Uji validitas merupakan kesahihan atau kevalidan suatu instrumen dalam sebuah penelitian dapat diuji menggunakan uji validitas. Instrumen dapat dikatakan valid apabila instrumen tersebut mampu mengukur serta menjelaskan data dari setiap variabel yang diteliti pada suatu penelitian dengan benar. Instrumen penelitian dikatakan valid pada uji validitas apabila r-hitung lebih besar daripada r-tabel dengan taraf signifikansi 0,05 dan instrumen dikatakan tidak valid apabila r-hitung lebih kecil dari r-tabel dengan taraf signifikansi 0,05.

Uji reabilitas pada penelitian ini digunakan untuk menunjukkan bahwa suatu instrumen cukup dapat dipercaya untuk alat pengumpulan data pada suatu penelitian. Instrumen penelitian dikatakan reliabel apabila nilai Cronhbach's Alpha lebih besar dari alpha dan instrumen dikatakan tidak reliabel apabila nilai Cronhbach's Alpha kurang dari alpha. Pada uji validitas dan reabilitas penelitian ini menggunakan aplikasi IBM SPSS Version 25 for Windows.

\subsection{Teknik Analisis Data}

Pada penelitian ini peneliti menggunakan teknis analisis data yang terdiri dari analisis data deskriptif setiap variabel, analisis regresi berganda, dan analisis data statistik inferensial terdiri dari uji normalitas, uji multikolinearitas, uji heterokedastisitas, uji hipotesis, koefisien determinasi, dan sumbangan efektif. Analisis data penelitian menggunakan aplikasi IBM SPSS Version 25 for Windows.

\section{Hasil dan Pembahasan}

\subsection{Hasil Penelitian}

Berdasarkan jawaban responden dari hasil penyebaran angket dan dilakukan analisis deskriptif data pada setiap variabel maka diperoleh hasil berbentuk tabel sebagai berikut.

\subsubsection{Variabel Literasi Ekonomi (X1)}

Tabel 1. Jawaban Responden Mengenai Pemahaman dan Penerapan Literasi Ekonomi

\begin{tabular}{lllll}
\hline No & \multicolumn{1}{c}{ Kategori } & \multicolumn{1}{c}{ Interval } & \multicolumn{1}{c}{ Frekuensi } & \multicolumn{1}{c}{ Persentase } \\
\hline 1 & A (Sangat baik) & $78-100$ & 11 & $17,00 \%$ \\
2 & B (Baik) & $52-77$ & 35 & $53,80 \%$ \\
3 & C (Cukup baik) & $26-51$ & 19 & $29,20 \%$ \\
4 & D (Kurang baik) & $0-25$ & 0 & $0 \%$ \\
Jumlah & & $\mathbf{6 5}$ & $\mathbf{1 0 0 \%}$ \\
\hline
\end{tabular}


Jurnal Ekonomi, Bisnis dan Pendidikan, 1(8), 2021, 746-752

Tabel 2. Hasil Deskripsi Data Variabel Literasi Ekonomi

Descriptive Statistics

\begin{tabular}{lrrrrrr}
\hline & N & Minimum & Maximum & \multicolumn{2}{c}{ Mean } & Std. Deviation \\
& Statistic & Statistic & Statistic & Statistic & Std. Error & Statistic \\
\hline x1 & 65 & 25 & 95 & 57.00 & 2.260 & 18.217 \\
Valid N (listwise) & 65 & & & & & \\
\hline
\end{tabular}

Dari tabel di atas dapat diketahui bahwa 65 responden, diperoleh skor terendah 25 dan tertinggi 95 dengan skor rata-rata sebesar 57,00. Simpangan baku atau standar deviasi sebesar $18,217$.

\subsubsection{Variabel Literasi Keuangan (X2)}

Tabel 3. Jawaban Responden Mengenai Pemahaman dan Penerapan Literasi Keuangan

\begin{tabular}{lllll}
\hline No & \multicolumn{1}{c}{ Kategori } & \multicolumn{1}{c}{ Interval } & \multicolumn{1}{c}{ Frekuensi } & \multicolumn{1}{c}{ Presentase } \\
\hline 1 & A (Sangat baik) & $48-60$ & 25 & $38,46 \%$ \\
2 & B (Baik) & $37-47$ & 31 & $47,70 \%$ \\
3 & C (Cukup baik) & $26-36$ & 9 & $13,84 \%$ \\
4 & D (Kurang baik) & $15-25$ & 0 & $0 \%$ \\
Jumlah & & 65 & $100 \%$ \\
\hline
\end{tabular}

Tabel 4. Hasil Deskripsi Data Variabel Literasi Keuangan

\section{Descriptive Statistics}

\begin{tabular}{lllllll} 
& \multicolumn{1}{c}{ N } & Minimum & Maximum & \multicolumn{2}{c}{ Mean } & Std. Deviation \\
& Statistic & Statistic & Statistic & Statistic & Std. Error & Statistic \\
\hline x2 & 65 & 32 & 56 & 45.18 & .833 & 6.713 \\
Valid N (listwise) & 65 & & & & & \\
\hline
\end{tabular}

Dari tabel di atas dapat diketahui bahwa 65 responden, diperoleh nilai terendah 32 dan tertinggi 56 dengan skor rata-rata sebesar 45,18. Simpangan baku atau standar deviasi sebesar 6,713 .

\subsubsection{Variabel Sikap tentang Gaya Hidup Hedonis (Y)}

Tabel 5. Jawaban Responden Mengenai Pemahaman dan Penerapan Sikap tentang Gaya Hidup Hedonis

\begin{tabular}{lllll}
\hline No & \multicolumn{1}{c}{ Kategori } & Interval & \multicolumn{1}{c}{ Frekuensi } & \multicolumn{1}{c}{ Persentase } \\
\hline 1 & A (Sangat setuju) & $48-60$ & 41 & $63,1 \%$ \\
2 & B (Setuju) & $37-47$ & 1 & $1,53 \%$ \\
3 & C (Tidak setuju) & $26-36$ & 9 & $13,84 \%$ \\
4 & D (Sangat tidak setuju) & $15-25$ & 14 & $21,53 \%$ \\
Jumlah & & & 65 & $100 \%$ \\
\hline
\end{tabular}


Jurnal Ekonomi, Bisnis dan Pendidikan, 1(8), 2021, 746-752

Tabel 6. Hasil Deskripsi Data Variabel Sikap tentang Gaya Hidup Hedonis

\section{Descriptive Statistics}

\begin{tabular}{lllcccc}
\hline \multicolumn{1}{c}{$\begin{array}{c}\text { N } \\
\text { Statistic }\end{array}$} & Minimum & Maximum & \multicolumn{2}{c}{ Mean } & Std. Deviation \\
& Statistic & Statistic & Statistic & Std. Error & Statistic \\
\hline $\mathrm{Y}$ & 65 & 21 & 55 & 41.78 & 1.608 & 12.966 \\
Valid N (listwise) & 65 & & & & & \\
\hline
\end{tabular}

Dari tabel di atas dapat diketahui bahwa dari 65 responden, diperoleh skor terendah 21 dan tertinggi 55 dengan skor rata-rata sebesar 41,78. Simpangan baku atau standar deviasi sebesar 12,966 .

\subsection{Pembahasan}

Hasil penelitian menunjukkan bahwa mahasiswa aktivis UKM Organisasi Pecinta Musik (OPUS) 275 Universitas Negeri Malang berada pada kategori baik yang artinya mahasiswa memiliki pemahaman yang pada mengenai literasi ekonomi dan literasi keuangan. Hal ini dibuktikan pada tabel 1, jawaban responden variabel literasi ekonomi dengan persentase $53,80 \%$ yang berada pada kategori baik. Pada tabel 3, jawaban responden variabel literasi keuangan dengan persentase $47,70 \%$ yang berada pada kategori baik.

Pada penelitian ini dilakukan uji regresi linier berganda dengan menggunakan aplikasi IBM SPSS Version 25 for Windows untuk mengetahui pengaruh parsial variabel bebas terhadap variabel terikat dengan persamaan $\mathrm{Y}=86,305+(-0,514) \mathrm{X}_{1}+(-0,337) \mathrm{X}_{2}+e$ yang berarti nilai konstanta. Apabila variabel independen literasi ekonomi dan literasi keuangan sama dengan nol maka besarnya variabel sikap tentang gaya hidup hedonis $(\mathrm{Y})$ sebesar 86,305. Koefisien regresi variabel literasi ekonomi $\left(\mathrm{X}_{1}\right)$ sebesar 0,514 . Hal ini menunjukkan bahwa ketika nilai koefisien literasi ekonomi $\left(\mathrm{X}_{1}\right)$ mengalami kenaikan sebesar 1 unit, maka sikap tentang gaya hidup hedonis ( $\mathrm{Y}$ ) diprediksi turun sebesar $-0,514$ unit dengan asumsi variabel lainnya tetap. Koefisien regresi variabel literasi keuangan $\left(\mathrm{X}_{2}\right)$ sebesar - 0,337. Hal ini menunjukkan bahwa ketika nilai koefisien literasi ekonomi $\left(\mathrm{X}_{2}\right)$ mengalami kenaikan sebesar 1 unit, maka sikap tentang gaya hidup hedonis $(\mathrm{Y})$ diprediksi turun sebesar -0,337 unit.

Dari hasil analisis uji regresi berganda dapat disimpulkan bahwa literasi ekonomi tidak berpengaruh signifikan terhadap sikap tentang gaya hidup hedonis. Hal ini juga dibuktikan dengan hasil analisis uji t (parsial) bahwa thitung $(-8,888)<$ tabel $(2,000)$ dan Sig. $(0,000)<0,05$, maka dapat disimpulkan bahwa $\mathrm{H}_{0}$ diterima yang artinya variabel literasi ekonomi tidak berpengaruh dan signifikan terhadap variabel sikap terhadap gaya hidup hedonis mahasiswa. Variabel literasi keuangan juga tidak berpengaruh terhadap sikap tentang gaya hidup hedonis, seperti hasil analisis uji t (parsial) menyatakan thitung $(-2,146)<t_{\text {tabel }}(2,000)$ dan Sig. $(0,036)$ $<0,05$ maka dapat disimpulkan $\mathrm{H}_{0}$ diterima yang artinya bahwa variabel literasi keuangan $\left(\mathrm{X}_{2}\right)$ tidak berpengaruh dan signifikan terhadap variabel sikap tentang gaya hidup hedonis mahasiswa (Y).

Berbeda dengan hasil analisis uji t (parsial), pada hasil analisi uji $f$ (simultan) menyatakan literasi ekonomi dan literasi keuangan berpengaruh signifikan terhadap sikap 
tentang gaya hidup hedonis. Hal ini dibuktikan dengan hasil analisis IBM SPSS Version 25 for Windows menyatakan nilai F Fitung $(53,838)>F_{\text {tabel }}(2,758)$ dan Sig. $(0,000)<0,05$, maka dapat disimpulkan $\mathrm{H}_{0}$ ditolak dan $\mathrm{H}_{1}$ diterima yang artinya bahwa terdapat pengaruh dan signifikan literasi ekonomi $\left(\mathrm{X}_{1}\right)$ dan literasi keuangan $\left(\mathrm{X}_{2}\right)$ terhadap sikap tentang gaya hidup hedonis mahasiswa $(Y)$.

Hasil penyebaran angket penelitian variabel literasi ekonomi dan literasi keuangan mahasiswa aktivis UKM Organisasi Pecinta Musik (OPUS) 275 pada kategori baik, namun pada variabel sikap tentang gaya hidup hedonis berada pada kategori tinggi. Hasil jawaban responden terbanyak memilih kategori sangat setuju bergaya hidup hedonis dengan persentase $63,1 \%$. Hal ini menunjukkan bahwa meskipun mahasiswa memiliki pemahaman literasi ekonomi dan literasi keuangan yang baik namun mereka tetap memiliki gaya hidup hedonis yang tinggi. Pemahaman literasi ekonomi yang dimiliki hanya digunakan sebagai pengetahuan namun tidak diterapkan untuk kehidupan sehari-hari. Hal ini dikarenakan adanya modernisasi yang mampu merubah gaya hidup mahasiswa ke arah hedonis. Mahasiswa tidak lagi membeli barang yang mereka butuhkan melainkan membeli barang karena keinginan dan mengikuti tren yang sedang berlangsung. Kegiatan berbelanja sangat dipermudah karena adalahnya e-commerce yang menyediakan fasilitas membeli tanpa pergi ke toko dan menyediakan jasa kirim barang, serta lingkungan pertemanan yang mengutamakan kesenangan dalam hidup.

Argumen diatas didukung oleh penelitian Rahayu, Asriati, dan Syahrudin (2017) yang menyatakan bahwa siswa kelas XI IPS sudah tergolong masyarakat yang tidak lagi mementingkan pengetahuan dasar ekonomi atau rasionalitas melainkan didasarkan oleh keinginan agar mengikuti tren dan berdasarkan keinginan semata. Hal ini juga selaras dengan yang dikatakan oleh Pawanti (2013) bahwa barang elektronik, fast food, pakaian bermerek, dan lain-lain sepertinya kini menjadi sebuah kebutuhan primer dan tidak dapat ditinggalkan. Masyarakat tidak lagi membeli barang berdasarkan skala prioritas dan kegunaan, tetapi lebih didasarkan pada gengsi, pretise, dan gaya (dalam Rahayu, Asriati, Syahrudin, 2017).

Pada literasi keuangan, mahasiswa hanya digunakan sebagai pengetahuan. Seperti yang diungkapkan oleh Hasil penelitian ini selaras dengan pernyataan Sari dan Andriani (2019), Huston (2010) (dalam Astriani, 2018), dan Hapsari (2012). Pada penelitian ini menunjukkan bahwa memiliki tingkat pemahaman literasi keuangan yang baik juga memiliki tingkat gaya hidup hedonis yang tinggi pula. Dengan perkembangan zaman yang semakin pesat terdapat faktor-faktor yang menyebabkan hal itu terjadi, salah satunya seperti pengaruh teman sebaya. Mahasiswa akan mengusahakan dirinya agar terlihat setara dengan kelompok temannya. Meskipun memiliki pemahaman literasi keuangan yang baik namun mereka mengutamakan keinginan yang harus terpenuhi. Hal ini diungkap oleh Anifah (2020) yang menyatakan literasi keuangan berpengaruh positif terhadap gaya hidup karena pengaruh teman-teman sebaya yang mana mahasiswa akan berusaha setara dengan temannya, sehingga walaupun mereka memiliki literasi keuangan yang tinggi gaya hidup juga tetap tinggi bahkan mengarah ke hedonis. Uraian tersebut didukung oleh pernyataan Aryani, Yulaika, dan Wikanso (2021) dalam penelitiannya yang menyatakan literasi financial secara parsial berpengaruh terhadap shopping lifestyle mahasiswa Universitas PGRI Madiun tahun akademik 2019/2020 dengan adanya intensitas gadget yang mempermudah mahasiswa memperoleh informasi dari berbagai belahan dunia, kemudian membentuk shopping lifestyle. 


\section{Simpulan}

Berdasarkan hasil penelitian maka dapat disimpulkan sebagai berikut 1) literasi ekonomi tidak berpengaruh signifikan terhadap sikap tentang gaya hidup hedonis mahasiswa aktivis UKM Organisasi Pecinta Musik (OPUS) 275 Universitas Negeri Malang. Hal ini dikarenakan adanya modernisasi yang mampu merubah gaya hidup mahasiswa ke arah hedonis. Mahasiswa tidak lagi membeli barang yang mereka butuhkan melainkan membeli barang karena keinginan dan mengikuti tren yang sedang berlangsung seperti barang elektronik, fast food, pakaian bermerek, dan lain-lain yang kini menjadi sebuah kebutuhan primer dan tidak dapat ditinggalkan. 2) Literasi keuangan tidak berpengaruh signifikan terhadap sikap tentang gaya hidup hedonis mahasiswa aktivis UKM Organisasi Pecinta Musik (OPUS) 275 Universitas Negeri Malang. Hal ini dikarenakan adanya pengaruh teman-teman sebaya yang mana mahasiswa akan berusaha setara dengan temannya dan juga adanya intensitas gadget yang mempermudah mahasiswa memperoleh informasi dari berbagai belahan dunia, kemudian membentuk shopping lifestyle. 3) Literasi ekonomi dan literasi keuangan berpengaruh signifikan terhadap sikap tentang gaya hidup hedonis mahasiswa aktivis UKM Organisasi Pecinta Musik (OPUS) 275 Universitas Negeri Malang.

\section{Daftar Rujukan}

Anifah, s. (2020). Pengaruh literasi keuangan, kontrol diri dan religiusitas terhadap perilaku konsumtif dengan gaya hidup sebagai variable intervening (Studi pada Mahasiswa Fakultas Ekonomi dan Bisnis Islam IAIN Salatiga).

Aryani, N., \& Yulaika, R. (2021). Pengaruh Literasi Finansial dan Intensitas Penggunaan Gadget Terhadap Shopping Lifestyle Mahasiswa Universitas PGRI Madiun Tahun Akademik 2019/2020. EQUILIBRIUM: Jurnal Ilmiah Ekonomi dan Pembelajarannya, 9(1), 14-25.

Eka, A., \& Harsono, S. U. (2018). Gaya Hidup Ditinjau Dari Lingkungan Pergaulan Dan Literasi Keuangan Mahasiswa Program Studi Pendidikan Akuntansi Universitas Muhammadiyah Surakarta Angkatan 2014 (Doctoral dissertation, Universitas Muhammadiyah Surakarta).

Hapsari, E. I. (2012). Kekuatan rasio keuangan dalam memprediksi kondisi financial distress perusahaan manufaktur di BEI. JDM Jurnal Dinamika Manajemen, 3(2).

Haryono, A. (2013). Pengaruh Persepsi Proses Pembelajaran, Penilaian dan Status Sosial Ekonomi Terhadap Literasi Ekonomi Siswa SMA. Jurnal Pendidikan dan Pembelajaran (JPP), 20(1), 09-17.

Keuangan, O. J. (2017). Otoritas Jasa Keuangan. Salinan Peraturan Otoritas Jasa Keuangan.

Keuangan, O. J. (2017). Survey nasional literasi dan inklusi jasa keuangan 2016. Jakarta: Otoritas Jasa Keuangan.

Nadzir, M., \& Ingarianti, T. M. (2015). Psychological meaning of money dengan gaya hidup hedonis remaja di kota Malang. In Psychologi Forum UMM (1998) (pp. 978-79).

Priansa, D. J. (2017). Perilaku Konsumen dalam Persaingan Bisnis Kontemporer. Bandung: Alfabeta.

Purnama, H. M., \& Yuliafitri, I. (2019). Efektivitas Gerakan Literasi Keuangan Syariah Dalam Mengedukasi Masyarakat Memahami Produk Keuangan Syariah. Banque Syar'i: Jurnal llmiah Perbankan Syariah, 5(1).

Rahayu, A. (2017). Pengaruh Literasi Ekonomi dan Modernitas terhadap Perilaku Konsumsi Siswa Kelas XI IPS Sman 1 Segedong. Jurnal Pendidikan dan Pembelajaran Khatulistiwa, 6(10).

Sari, N. E., \& Andriani, D. N. (2019). Gaya Hidup Hedonis Ditinjau Dari Kecerdasan Finansial Mahasiswa Di Kota Madiun. EQUILIBRIUM: Jurnal Ilmiah Ekonomi dan Pembelajarannya, 7(1), 21-26.

Solihat, A. N., \& Arnasik, S. (2018). Pengaruh Literasi Ekonomi Terhadap Perilaku Konsumtif Mahasiswa Jurusan Pendidikan Ekonomi Universitas Siliwangi. Oikos: Jurnal Ekonomi dan Pendidikan Ekonomi, 2(1), 1-13.

Suryani, T. (2013). Perilaku Konsumen di Era Internet Implikasinya pada Strategi Pemasaran. Yogyakarta: Graha Ilmu.

Waluyo, F. I. A., \& Marlina, M. A. E. (2019). Peran Literasi Keuangan dalam Pengelolaan Keuangan Mahasiswa. 